\title{
Stress state in the upper crust around the source region of the 1891 Nobi earthquake through shear wave polarization anisotropy
}

Yoshihiro Hiramatsu ${ }^{1 *}$, Takashi lidaka ${ }^{2}$ and The Research Group for the Joint Seismic Observations at the Nobi Area $^{2}$

\begin{abstract}
We investigate shear wave polarization anisotropy in the upper crust around the source region of the 1891 Nobi earthquake, central Japan. At most stations, the orientation of the faster polarized shear wave is parallel to the axes of the maximum horizontal compressional strain rate and stress, indicating that stress-induced anisotropy is dominant in the analyzed region. Furthermore, near the source faults, the orientation of the faster polarized shear wave is oblique to the strike of the source faults. This suggests that microcracks parallel to the strike of the source fault, which would be produced by the fault movement of the Nobi earthquake, have healed with the healing of the faults. For stress-induced anisotropy, time delays normalized by path length in the anisotropic upper crust as a function of the differential strain rate are coincident with those in the inland high strain rate zone, Japan. These data, together with those of a previous study, show that the variation in the stressing rate, estimated from shear wave splitting, is close to that estimated from geodetic observation. This implies that the variation in the stressing rate in the brittle upper crust is linked to that in the strain rate on the ground surface.
\end{abstract}

Keywords: Shear wave splitting; High strain rate zone; Stressing rate; Brittle-ductile transition zone; Seismic anisotropy; Inland earthquake

\section{Findings}

Introduction

Shear wave splitting is a phenomenon induced by seismic anisotropy due to the preferred orientation of microcracks or minerals, or a layered structure with different seismic wave velocities. Shear waves split into two orthogonal wavelets, one traveling faster than the other, in anisotropic media. Shear wave splitting is, therefore, expressed by two splitting parameters: the polarization orientation of the faster wavelet $\phi$ and the time delay between the two wavelets $\delta t$. In the case of the preferred orientation of microcracks, a temporal variation in shear wave splitting induced by a stress change in the crust is often accompanied by earthquakes (e.g., Liu et al. 1997; Saiga et al. 2003) or volcanic activities (e.g., Miller and Savage 2001; Savage et al. 2010; Roman et al. 2011; Honda et al. 2014). Furthermore,

\footnotetext{
* Correspondence: yoshizo@staff.kanazawa-u.ac.jp

${ }^{1}$ Faculty of Natural System, Institute of Science and Engineering, Kanazawa

University, Kakuma, Kanazawa, Ishikawa 920-1192, Japan

Full list of author information is available at the end of the article
}

detailed observations have revealed a healing process of microcracks in the crust, after an earthquake, through shear wave splitting (Tadokoro and Ando 2002; Hiramatsu et al. 2005).

A dense network of global positioning system (GPS) observations has revealed a high strain rate zone, where the strain rate is one order larger than that of the surrounding areas, known as the Niigata-Kobe Tectonic Zone, in central Japan (Sagiya et al. 2000) (Figure 1). This high strain rate zone is characterized seismically by a low velocity in the lower crust (Nakajima and Hasegawa 2007; Matsubara et al. 2008) and a low coda $Q$ at lower frequency band around 1 to $2 \mathrm{~Hz}$ (Jin and Aki 2005; Hiramatsu et al. 2013; Tsuji et al. 2014). Hiramatsu et al. (2010) investigated a spatial distribution of shear wave splitting in and around this zone. They simply categorized the observed shear wave splitting into two types: stress-induced anisotropy and structure-induced anisotropy. The stressinduced anisotropy shows that $\phi$ is parallel to the axis of the maximum horizontal compressional stress estimated 


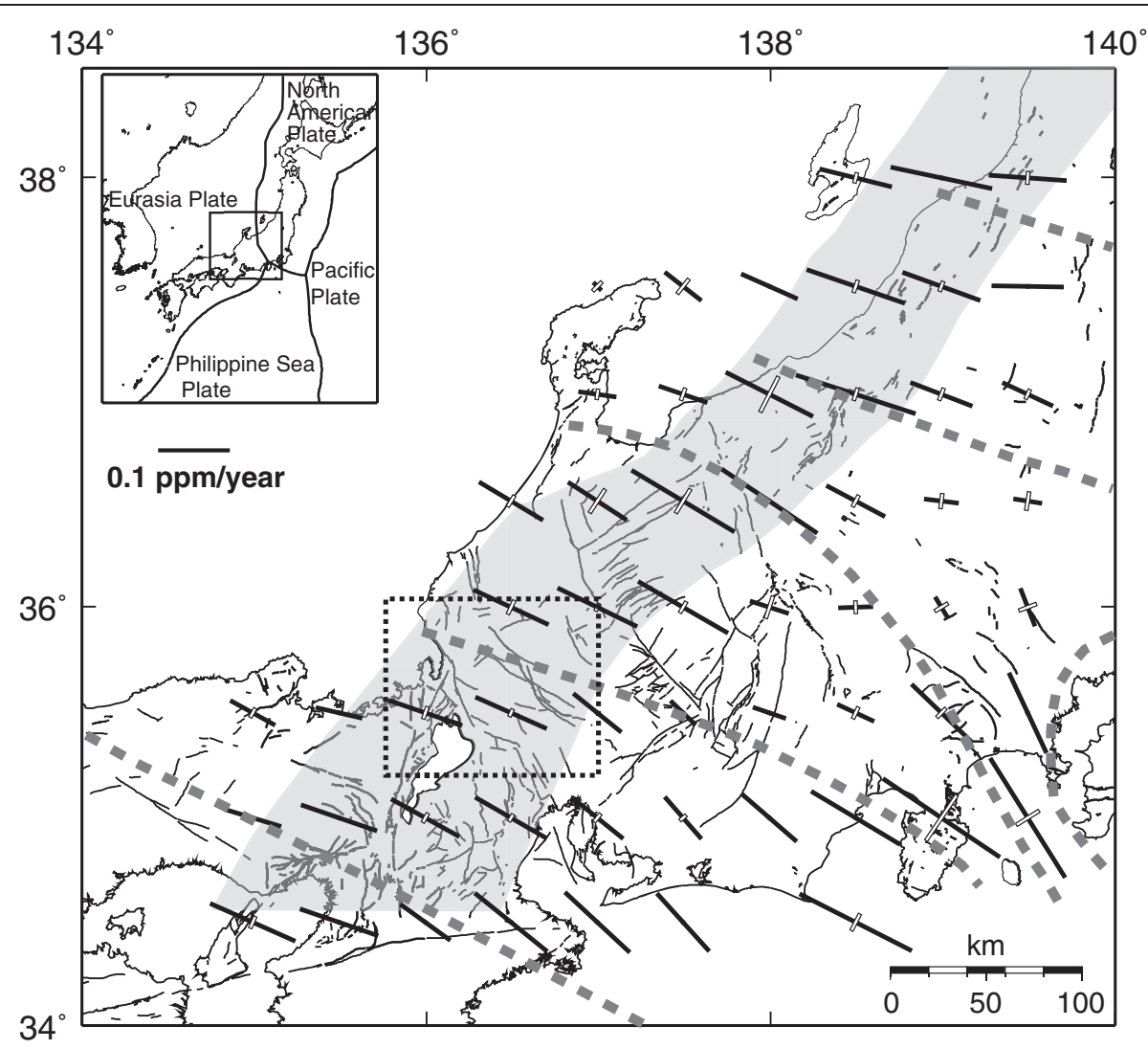

Figure 1 Tectonic map (modified from Figure 1 of Hiramatsu et al. (2010). Distribution of the principal strain rate axes (black bars: compression, white bars: extension), the high strain rate zone called the Niigata-Kobe Tectonic Zone (gray zone) (Sagiya et al. 2000), the trajectories of the maximum horizontal compressional stress (Ando 1979) (gray dashed lines), Quaternary active faults (lines). A dotted rectangle shows the analyzed region of this study shown in Figure 2.

from focal mechanisms of crustal earthquakes and strikes of dykes and Quaternary active faults (Ando 1979), which has been confirmed by in situ stress measurements and focal mechanisms (Tsukahara and Ikeda 1991) and inversion of focal mechanisms from recent high-quality initial motion data (Townend and Zoback 2006) and from centroid moment tensor data (Terakawa and Matsu'ura 2010), or to the axis of the maximum horizontal compressional strain rate estimated from GPS data (Sagiya et al. 2000) (Figure 1). On the other hand, the structureinduced anisotropy shows $\phi$ is parallel to the strike of active faults. For the stress-induced anisotropy, Hiramatsu et al. (2010) showed that the normalized time delay by path length is proportional to the differential strain rate obtained by GPS observations and estimated a spatial variation in the stressing rate of $3 \mathrm{kPa} /$ year in the upper crust in and around the high strain rate zone.

One of the features of the high strain rate zone is the occurrence of inland large earthquakes (Sagiya et al. 2000). The source region of the 1891 Nobi earthquake (M8.0), which is the largest class of inland earthquakes in Japan, lies in the high strain rate zone (Figure 2). To promote an understanding of the generation process of inland earthquakes, the Research Group for the Joint Seismic Observations at the Nobi Area deploys seismic stations densely around the source region. Seismic waveform data from the dense seismic network is useful for the investigation of seismic structures from the crust to the upper mantle, the focal mechanism of microearthquakes, crustal heterogeneity such as coda $Q$, and the state of the crustal stress through shear wave splitting.

We report here a detailed spatial distribution of shear wave splitting using the dense seismic network, providing a stress state in the upper crust around the source region. Furthermore, we examine a proportional relation between the normalized time delay and the differential strain rate from GPS data observed previously in and around the high strain rate zone (Hiramatsu et al. 2010) based on shear wave splitting data around the source region.

\section{Data and method}

We analyze the waveform data of earthquakes with magnitude $\geq 1.0$ and focal depth $\leq 20 \mathrm{~km}$, from May 2009 to October 2011, recorded at stations of the Research Group 


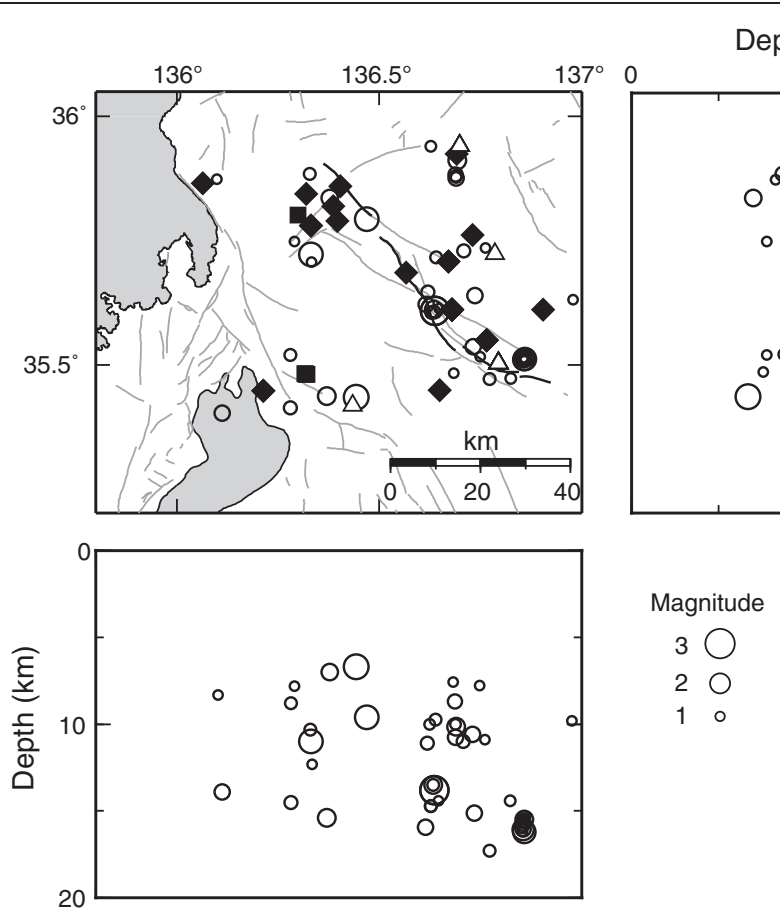

Figure 2 Distribution of earthquakes (circles) and stations used in this study. Diamonds, squares, and triangles indicate stations of The Research Group for the Joint Seismic Observations at the Nobi Area, Kyoto University, and NIED, respectively. Gray lines are Quaternary active faults. Black lines show the source fault of the 1891 Nobi earthquake.

for the Joint Seismic Observations at the Nobi Area, the Japan Meteorological Agency, the National Research Institute for Earth Sciences and Disaster Prevention (NIED), the Disaster Prevention Research Institute, Kyoto University, and the Research Center for Seismology, Volcanology and Disaster Mitigation, Nagoya University. The hypocenter catalogue of the Japan Meteorological Agency is used to select earthquakes that satisfy the above conditions.

We restrict ray paths to those having incident angle to ground surface $\leq 35^{\circ}$ to minimize the effect of phase conversion from $\mathrm{S}$ to $\mathrm{P}$, or the distortion of particle motions at the free surface (Booth and Crampin 1985). The S wave velocity structure model of area 3 of Hiramatsu et al. (2010) is used to calculate the ray paths and those lengths because the analyzed area is almost the same. The distribution of events and stations used in this study is shown in Figure 2.

An example of shear wave splitting analysis is shown in Figure 3. The covariance matrix decomposition method (Silver and Chan 1991) is applied to estimate the splitting parameters of $\delta t$ and $\phi$ and those confidence ranges from the band-pass filtered ( 1 to $20 \mathrm{~Hz}$ ) two horizontal components of $\mathrm{S}$ waves. Together with this method, we examine the particle motion visually and confirm that the initial motion of $S$ waves is coincident with the estimated splitting parameters. As a result, we obtain a total of 50 measurements of shear wave splitting at 21 stations from 49 events (Figures 2 and 4).

\section{Spatial distribution of polarization orientation}

We show a spatial distribution of splitting parameters from each event at each station in Figure 4. The observed polarization orientation, $\phi$, ranges from E-W to NW-SE. In this study, we use two stations for which waveform data are analyzed by Hiramatsu et al. (2010). At these stations, we obtain almost the same $\phi$ as reported by Hiramatsu et al. (2010) (Figure 4).

The observed $\phi$ is coincident with the orientation of the regional maximum horizontal compressional stress axis in this region (Ando 1979; Tsukahara and Ikeda 1991; Townend and Zoback 2006; Terakawa and Matsu'ura 2010) or the axis of maximum horizontal compressional strain rate estimated from continuous GPS data (Sagiya et al. 2000). This fact indicates that the preferred alignment of microcracks that causes shear wave splitting is induced by the regional stress.

Tadokoro and Ando (2002) performed a shear wave splitting analysis on the Nojima fault, which is one of the source faults of the 1995 Hyogo-ken Nanbu earthquake, in Japan. They observed a fault parallel $\phi$ for a period of 9 to 12 months after the mainshock, and a fault oblique $\phi$ for a period of 33 to 45 months after the 

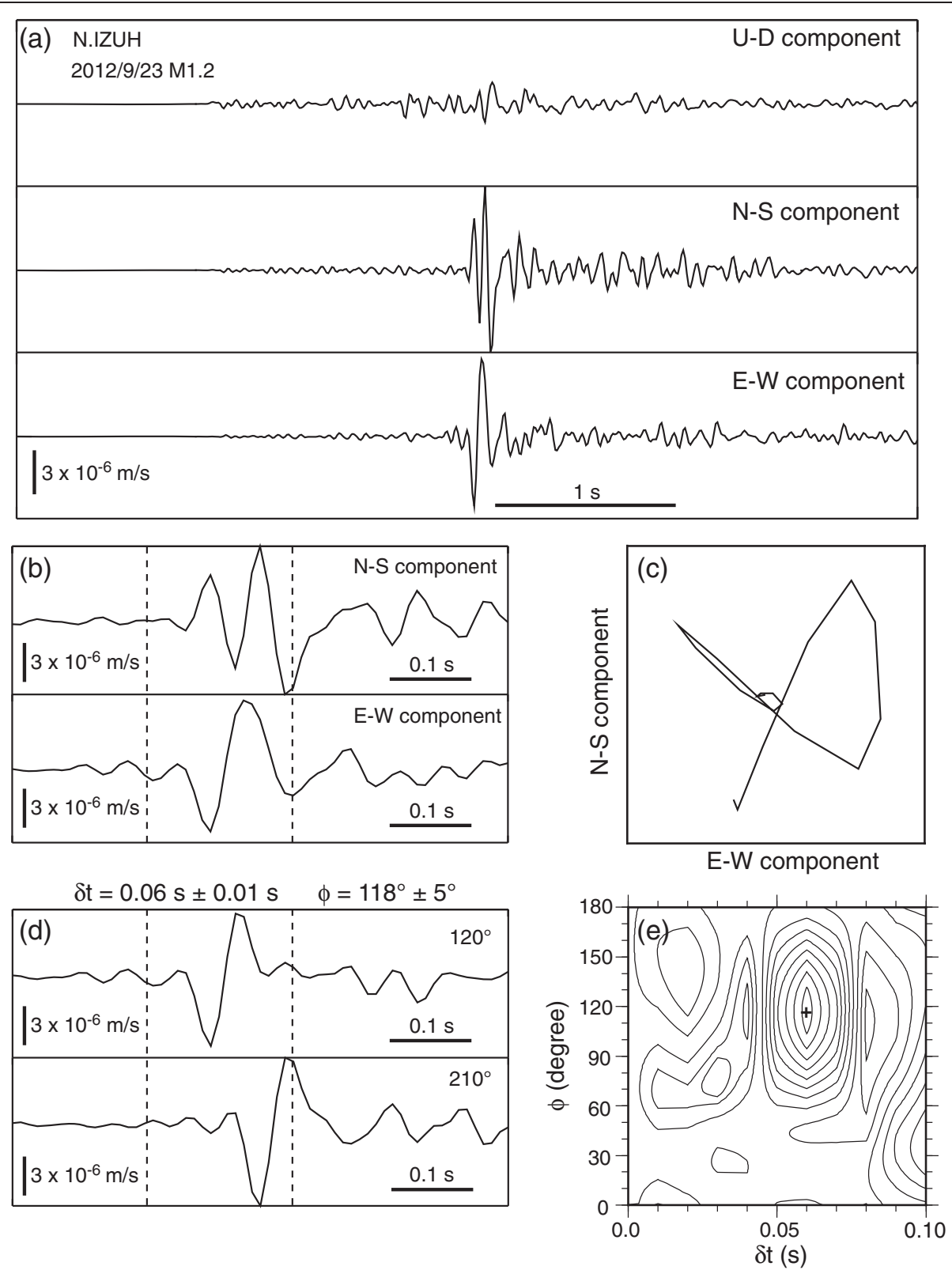

Figure 3 An example of shear wave splitting analysis. (a) An example of band-pass (1 to $20 \mathrm{~Hz}$ ) filtered three component waveform data at station $\mathrm{N}$. IZUH. (b) Original waveforms of band-pass filtered two horizontal components around the $\mathrm{S}$ wave. Dashed lines show the time window for particle motion and splitting analysis. (c) Particle motion of two horizontal components. (d) Rotated waveforms of a faster shear wave and a slower one. (e) Contour map of the confidence level by the method of Silver and Chan (1991). The plus sign shows the optimum splitting parameters of $\delta t$ and $\phi$. A contour interval corresponds to the confidence level of two times the standard error. Note that a variation of the confidence level along $\delta t$ axis finer than a sampling interval $(=0.01 \mathrm{~s})$ is artificial.

mainshock. They suggested that all the fractures of shear fault origin had completely healed and cracks of tectonic stress origin recovered between the two periods.

In this study, we obtain a fault oblique $\phi$ at the stations along the source fault of the 1891 Nobi earthquake (Figure 4), suggesting that the process of healing would have eliminated fractures parallel to the fault strike induced by shear faulting, if produced, accompanied with the 1891 Nobi earthquake.

\section{Relation between strength of anisotropy and strain rate}

The delay time, $\delta t$, observed in this study is displayed in Figure 4. The observed time delay is up to $0.1 \mathrm{~s}$, showing a consistency with the typical value of $\delta t$ of crustal anisotropy 


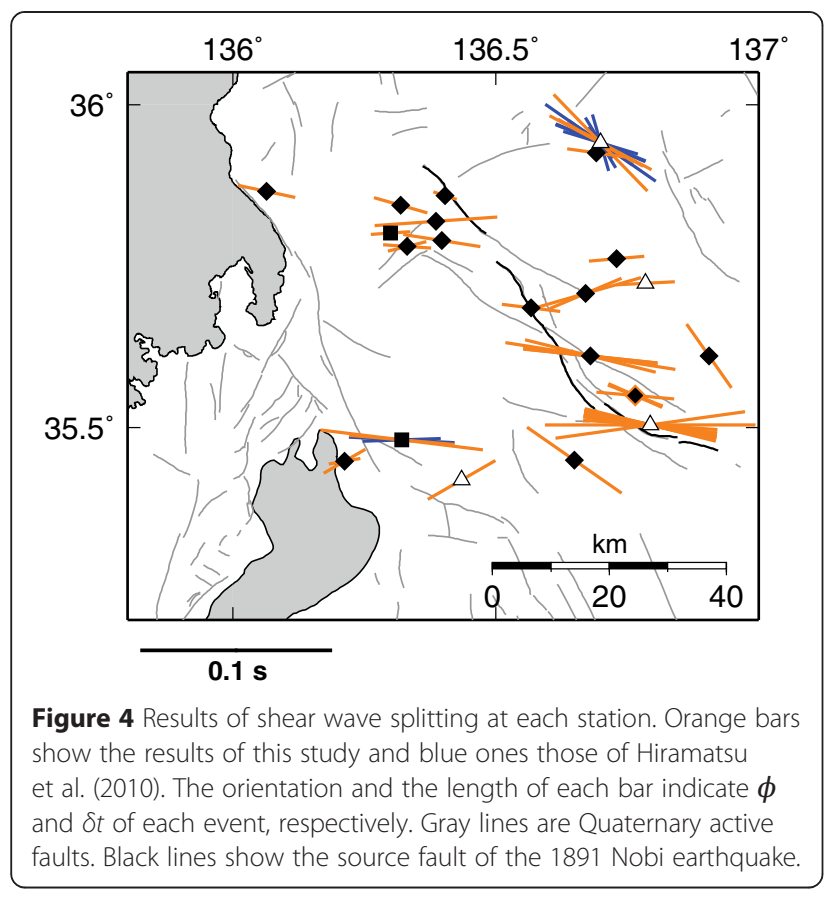

(Kaneshima 1990) and previous work in and around the high strain rate zone in Japan (Hiramatsu et al. 2010). At two stations that were considered in Hiramatsu et al. (2010), we obtain almost the same $\delta t$ as they reported.

To evaluate the strength of crustal anisotropy, the time delay normalized by the path length in the anisotropic layer is more suitable than the time delay itself. Figure 5 shows the relation between focal depth and $\delta t$ observed in this study. We can recognize that $\delta t$ tends to be large as the focal depth becomes deep, although the scatter is large. The average value of $\delta t$ for events with focal depth shallower than $12.5 \mathrm{~km}$ is $0.04 \pm 0.02 \mathrm{~s}$ and that deeper than $12.5 \mathrm{~km}$ is $0.06 \pm 0.02 \mathrm{~s}$ (Figure 5). Thus, we assume simply that all ray paths lie in the anisotropic layer, and we obtain the normalized time delay, $\delta t_{n}$, by dividing the time delay by the path length. This assumption is coincident with the result of Kaneshima (1990) who reported that an increase in $\delta t$ with depth was obvious for events with focal depth up to $15 \mathrm{~km}$ and crustal anisotropy existed in the upper 15 to $25 \mathrm{~km}$ in the crust in Japan. This suggests that not only open cracks but also inclusion, such as fluid-filled cracks, contributes to the crustal anisotropy because inclusions prevent from closing cracks under high confining pressure at deeper parts in the crust.

Figure 6 shows the spatial distribution of the average $\phi$ and the average $\delta t_{n}$ at each station. Following Hiramatsu et al. (2010), we focus on the stations whose angular difference between the average $\phi$ and the orientation of the principal compressional axis of the strain rate (Sagiya et al. 2000) is within $30^{\circ}$ because such stations are considered to show the stress-induced anisotropy. The angular
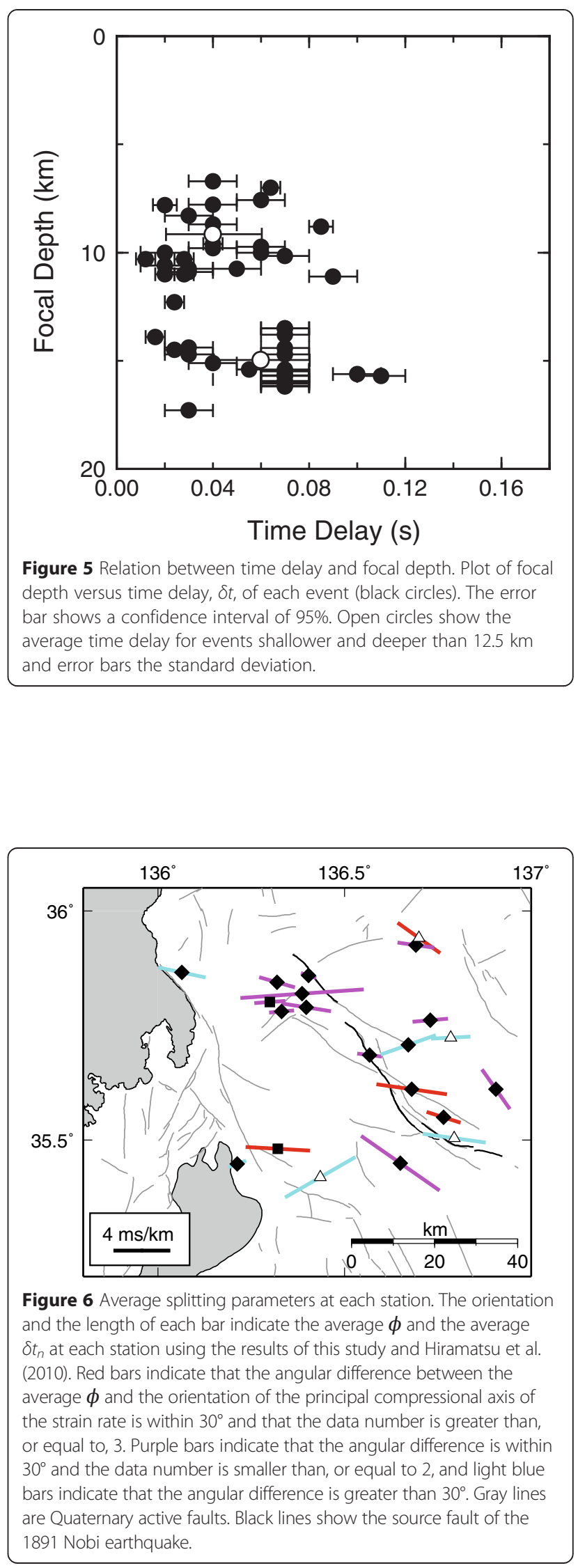
differences larger than $30^{\circ}$ may be caused by local perturbation of stress filed from the regional one, a contribution of anisotropy of preferred orientation of minerals, or a small number of data. Hiramatsu et al. (2010) reported a positive correlation between the differential strain rate and $\delta t_{n}$ in and around the high strain rate zone. The analyzed region of this study is included in the region of Hiramatsu et al. (2010). Thus, we compare the average $\delta t_{n}$ of the stressinduced anisotropy of this study to that of Hiramatsu et al. (2010) using the stations for which the data number is greater than, or equal to, 3 (red bars in Figure 6).

Figure 7 shows the relation between the differential strain rate and $\delta t_{n}$ of this study and that of Hiramatsu et al. (2010). We recognize that the data of this study are coincident with those in and around the high strain rate zone and that there is a positive correlation between $\delta t_{n}$ and the differential strain rate. This implies that the crustal stress accumulates corresponding to the differential strain rate observed on the ground surface in this region. Hiramatsu et al. (2010) proposed a formula to estimate the spatial variation in the stressing rate based on this proportional relation as follows:

$$
\dot{\sigma}=\frac{1}{R S C_{S P}} \frac{\Delta \delta t_{n}}{\delta t_{n}} \frac{1}{T_{C}}
$$

where $\dot{\sigma}$ is the spatial variation in the stressing rate, $R S C_{S P}$ is the response of the normalized time delay per unit stress change, $\Delta \delta t_{n} / \delta t_{n}$ is the fractional change of

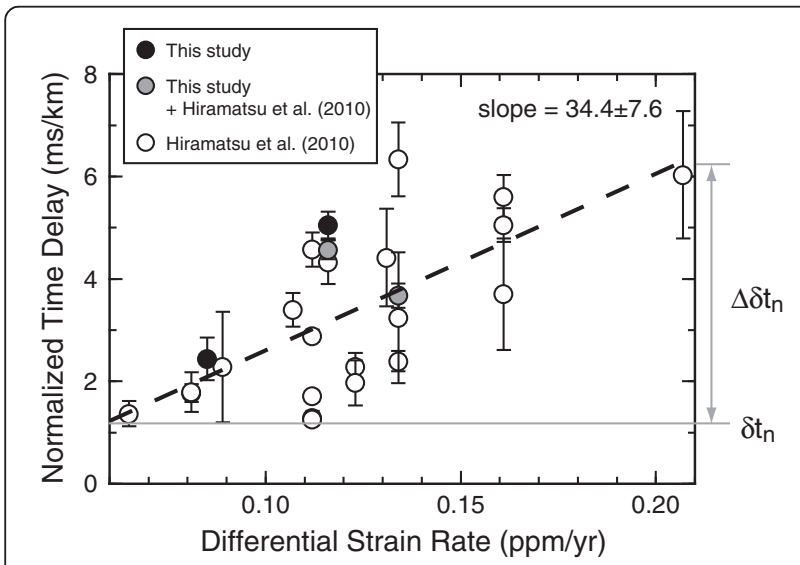

Figure 7 Relation between differential strain rate and normalized time delay. Plot of the differential strain rate observed by GPS (Sagiya et al. 2000) versus the average normalized time delay, $\delta t_{n}$, at stations for which the angular difference between the average $\phi$ and the orientation of the principal compression axis of the strain rate is within $30^{\circ}$ and the data number is greater than or equal to 3. Black, gray, and open circles are the data of this study, the combination of this study and Hiramatsu et al. (2010), and Hiramatsu et al. (2010), respectively. Each error bar shows a standard deviation of $\delta t_{n}$ at each station. The dashed line is the least squares fit to the data ( $\delta t_{n}=34.4 \times$ (differential strain rate)-0.81). Gray lines represent the definition of $\delta t_{n}$ and $\Delta \delta t_{n}$ in Equation 1. the normalized time delay in a region of interest, and $T_{C}$ is the characteristic time of the stress accumulation in the crust. Following Hiramatsu et al. (2010), we adopt here $R S C_{S P}=880 /(\mathrm{MPa})$ from the change in normalized time delays caused by the step-wise static stress change of a moderate size earthquake (Saiga et al. 2003; Hiramatsu et al. 2005) and $T_{C}=2$ years from the recovery of crack conditions to a step-wise static stress change (Hiramatsu et al. 2005; Sugaya et al. 2009).

We obtain a $\Delta \delta t_{n} / \delta t_{n}$ of 4.1 for the data shown in Figure 7 and substitute this in Equation 1, together with $R S C_{S P}$ and $T_{C}$ mentioned above, giving a $\dot{\sigma}$ of $2.3 \pm 0.5$ $\mathrm{kPa} /$ year in and around the high strain rate zone, which is almost coincident with a $\dot{\sigma}$ of $3.0 \pm 0.6 \mathrm{kPa} /$ year of the previous study (Hiramatsu et al. 2010). The difference in $\dot{\sigma}$ results mainly from the differences of $\delta t_{n}$ and the resulting $\Delta \delta t_{n} / \delta t_{n}$ between the two studies. In fact, the introduction of new data easily causes a change in the value of $\Delta \delta t_{n} / \delta t_{n}$ because of the large scatter of $\delta t_{n}$ as shown in Figure 7. We consider, therefore, that there is no significant difference between the two $\dot{\sigma}$. The differential strain rate of $0.15 \mathrm{ppm} /$ year provides a variation in stressing rate of $3 \mathrm{kPa} /$ year with a rigidity of $40 \mathrm{GPa}$ in the upper crust in and around the high strain rate zone in Japan (Hiramatsu et al. 2010). This value is close to that from the shear wave splitting in this study. We consider, therefore, that the variation in the stressing rate in the brittle upper crust is reflected mainly by the variation in the strain rate observed by GPS on the ground surface.

On the other hand, the stressing rate below the brittleductile transition zone in the crust is about five times larger than that in the brittle upper crust in and around the high strain rate zone from coda $Q$ analyses (Hiramatsu et al. 2010, 2013). This difference of the stressing rate in the brittle upper crust and below the brittle-ductile transition zone suggests a high ductile deformation rate below the brittle-ductile transition zone. Several kinematic models have been proposed for the cause of the high strain rate zone. A weak zone model, in which a weak zone with a lower viscosity exists in the lower crust, proposed by lio et al. (2002), is a plausible model from the point of view of the difference of the stressing rate in the brittle upper crust and below the brittleductile transition zone. In other words, the strain rate observed on the ground surface does not represent directly the strain rate in the ductile lower crust.

\section{Conclusions}

Shear wave splitting analyses have been performed using dense seismic network data around the source region of the 1891 Nobi earthquake, central Japan, to investigate the stress condition and crack healing near the faults. We observe an E-W to NW-SE orientation of the faster 
polarized shear wave at most stations, showing stressinduced anisotropy because this orientation is coincident with the axes of the maximum horizontal compressional strain rate and stress. We recognize that the orientation at stations near the source faults of the Nobi earthquake is oblique to the strike of the source faults, suggesting that microcracks parallel to the fault strike, that would be opened by the fault movement of the Nobi earthquake, has healed. Time delays of two split waves are typical for crustal anisotropy. For stress-induced anisotropy, time delays normalized by path length in this study are consistent with a proportional relation between time delays normalized by path length and the differential strain rate of the high strain rate zone estimated previously. The variation in the stressing rate is estimated from using the proportional relation between time delays normalized by path length and differential strain rate, giving $2.3 \mathrm{kPa} /$ year, which is close to the variation estimated from GPS observations. The variation in the stressing rate in the brittle upper crust is, therefore, a main cause of the variation in the stressing rate on the surface.

\section{Competing interests}

The authors declare that they have no competing interests.

\section{Authors' contributions}

YH conducted the analyses and drafted the manuscript. TI and RGJSONA participated in the design of this study and in the acquisition of data. All authors read and approved the final manuscript.

\section{Acknowledgements}

We thank the Japan Meteorological Agency, the National Research Institute for Earth Sciences and Disaster Prevention, the Disaster Prevention Research Institute, Kyoto University, and the Research Center for Seismology, Volcanology and Disaster Mitigation, Nagoya University for providing us with the waveform data. We are grateful to Suguru Urano and Tadashi Terada for their assistance in the analyses. Comments from anonymous reviewers are helpful to improve the manuscript. The GMT software (Wessel and Smith 1998) was used to produce the figures. This research was partly supported by a grant offered under the Earthquake Prediction Research Program of the Ministry of Education, Culture, Sports, Science and Technology of Japan, and it was also supported by the cooperative research program of the Earthquake Research Institute, The University of Tokyo.

\section{Author details}

${ }^{1}$ Faculty of Natural System, Institute of Science and Engineering, Kanazawa University, Kakuma, Kanazawa, Ishikawa 920-1192, Japan. ²Earthquake Research Institute, The University of Tokyo, Yayoi 1-1-1, Bunkyo, Tokyo 113-0032, Japan.

Received: 18 September 2014 Accepted: 27 March 2015 Published online: 17 April 2015

\section{References}

Ando M (1979) The stress field of the Japanese Islands in the last 0.5 million years. Earth Mon Symp 7:541-546 (in Japanese)

Booth DC, Crampin S (1985) Shear-wave polarizations on a curved wavefront at an isotropic free surface. Geophys J Roy Astron Soc 83:31-45

Hiramatsu Y, Honma H, Saiga A, Furumoto M, Ooida T (2005) Seismological evidence on characteristic time of crack healing in the shallow crust. Geophys Res Lett 32:L07305, doi: 10.1029/2007GL029391

Hiramatsu Y, Iwatsuki K, Ueyama S, lidaka T, The Japanese University Group of the Joint Seismic Observations at NKTZ (2010) Spatial variation in shear wave splitting of the upper crust in the zone of inland high strain rate, central Japan. Earth Planets Space 62:675-684
Hiramatsu Y, Sawada A, Yamauchi Y, Ueyama S, Nishigami K, Kurashimo E, The Japanese University Group of the Joint Seismic Observations at NKTZ (2013) Spatial variation in coda $Q$ and stressing rate around the Atotsugawa fault zone in a high strain rate zone, central Japan. Earth Planets Space 65:115-119

Honda R, Yukutake Y, Yoshida A, Harada M, Miyaoka K, Satomura M (2014) Stress-induced spatiotemporal variations in anisotropic structures beneath Hakone volcano, Japan, detected by S-wave splitting: A tool for volcanic activity monitoring. J Geophys Res. doi:10.1002/2014JB010978

lio Y, Sagiya T, Kobayashi Y, Shiozaki I (2002) Water-weakened lower crust and its role in the concentrated deformation in the Japanese Islands. Earth Planet Sci Lett 203:245-253

Jin A, Aki K (2005) High-resolution maps of coda Q in Japan and their interpretation by the brittle-ductile interaction hypothesis. Earth Planets Space 57:403-409

Kaneshima S (1990) Origin of crustal anisotropy: shear wave splitting studies in Japan. J Geophys Res 97:11121-11133

Liu Y, Crampin S, Main I (1997) Shear-wave anisotropy: spatial and temporal variations in time delays at Parkfield, Central California. Geophys J Int 130:771-785

Matsubara M, Obara K, Kasahara K (2008) Three-dimensional P-and S-wave velocity structures beneath the Japanese Islands obtained by high-density seismic stations by seismic tomography. Tectonophysics 454:86-103

Miller V, Savage MK (2001) Changes in seismic anisotropy after volcanic eruptions: Evidence from Mount Ruapehu. Science 293:2231-2233

Nakajima J, Hasegawa A (2007) Deep crustal structure along the Niigata-Kobe Tectonic Zone, Japan: Its origin and segmentation. Earth Planets Space 59:e5-e8

Roman DC, Savage MK, Arnold R, Latchman JL, De Angelis S (2011) Analysis and forward modeling of seismic anisotropy during the ongoing eruption of the Soufrière Hills Volcano, Montserrat, 1996-2007. J Geophys Res 116. doi:10.1029/2010JB007667

Sagiya T, Miyazaki S, Tada T (2000) Continuous GPS array and present-day crustal deformation of Japan. PAGEOPH 157:2003-2322

Saiga A, Hiramatsu Y, Ooida T, Yamaoka K (2003) Spatial variation in the crustal anisotropy and its temporal variation associated with the moderate size earthquake in the Tokai region, central Japan. Geophys J Int 154:695-705

Savage MK, Ohminato T, Aoki Y, Tsuji H, Greve S (2010) Stress magnitude and its temporal variation at Mt. Asama Volcano, Japan, from seismic anisotropy and GPS. Earth Planet Sci Lett 290. doi:10.1016/j.epsl.2009.12.037.

Silver PG, Chan WW (1991) Shear wave splitting and subcontinental mantle deformation. J Geophys Res 96:16429-16454

Sugaya K, Hiramatsu Y, Furumoto M, Katao H (2009) Coseismic change and recovery of scattering environment in the crust after the 1995 Hyogo-ken Nanbu earthquake, Japan. Bull Seismol Soc Am 99:435-440

Tadokoro K, Ando M (2002) Evidence for rapid fault healing derived from temporal changes in S wave splitting. Geophys Res Lett 29. doi:10.1029/ 2001GL013644

Terakawa T, Matsu'ura M (2010) The 3-D tectonic stress fields in and around Japan inverted from centroid moment tensor data of seismic events. Tectonics 29:TC6008, doi: 10.1029/2009TC002626

Townend J, Zoback MD (2006) Stress, strain, and mountain building in central Japan. J Geophys Res 111:B03411, doi:10.1029/2005JB003759

Tsuji S, Hiramatsu Y, The Japanese University Group of the Joint Seismic Observations at the Area of Nobi Earthquake (2014) Spatial variation in coda $\mathrm{Q}$ around the Nobi fault zone, central Japan: relation to S-wave velocity and seismicity. Earth Planets Space 66:97

Tsukahara H, Ikeda R (1991) Crustal stress orientation pattern in the central part of Honshu, Japan: Stress provinces and their origin. J Geol Soc Jpn 97:461-474 (in Japanese with English abstract)

Wessel P, Smith WHF (1998) New, improved version of Generic Mapping Tools released. EOS Trans Am Geophys Union 79:579 